\title{
From Conceptual Frameworks To Mental Models For Astronomy: Students' Perceptions
}

\author{
David Pundak, Kinneret College, Israel \\ Ido Liberman, Western Galilee College, Israel \\ Miri Shacham, Braude College, Israel
}

\begin{abstract}
Considerable debate exists among discipline-based astronomy education researchers about how students change their perceptions in science and astronomy. The study questioned the development of astronomical models among students in institutions of higher education by examining how college students change their initial conceptual frameworks and construct mental models in astronomy. The study considers four areas of astronomical knowledge: "sky observations," "Earth and its orbit," "solar system" and "stars" by implementing a recently developed research tool - Conceptual Frameworks in Astronomy (CFA) (Pundak, 2016). The responses of 537 undergraduates from three Israeli colleges were classified into one of four mental models: pre-scientific, geocentric, heliocentric, stellar/scientific. The findings indicate significant differences among students adopting some combination of the four mental models. Most students adopted a combination of these models and used different conceptual frameworks for different astronomical phenomena. Students with a scientific engineering background tended to use the stellar/scientific model more often than Liberal Arts students. The stellar/scientific model is the most scientifically progressive of the four models tested and manages the most systematic astronomical conceptual frameworks. The study identified three variables: "physical background," "average academic grade" and "academic discipline" - which contribute to the adoption of the stellar/scientific model.
\end{abstract}

Keywords: Astronomy Education Research; Mental Models; Cognition

$\mathscr{Q}$ ncertainty exist among discipline-based astronomy education researchers regarding precisely how astronomical knowledge develops among students. Some researchers are readily using the conceptual frameworks concept (Piage, 1973; Fingold \& Pundak, 1990, Sadler, 1998) while other researchers are using mental models to interpret student thinking (Gilbert, 2005; Hestenes, 2006; Lehrer \& Schauble, 2000). In this study, we are making an effort to make the distinction among these models of how thinking evolves in order to better understand how students learn astronomy.

The development of scientific conceptual frameworks (CFs) among children (Piaget, 1929; 1930; 1973) and especially the development of CFs for astronomy seems to be a gradual process. Research investigating how the youngest pupils in Grades 1-5 understand the phenomena of day and night identified nine development stages in the transition from naïve explanation to scientific explanation. Research on elementary school students' conceptualization of 'the solar system' identified seven models of 'the solar system' (Calderón, Flores \& Gallegos, 2013). These studies indicate that children develop their own models for astronomy through the learning process. In early age, children tend to adopt a culture-dependent pre-scientific approach; as they grow they adopt more advanced models that represent the development of a scientific approach based on the performance and interpretation of observations. Over human history, scientists and philosophers have attempted to address questions relating to the heavenly bodies such as: the source of starlight, the reasons for the movement of the sun, moon and stars, the phases of the moon, and the phenomenon of comets. They were especially curious about the influence of celestial bodies on human life. Four mental models (Vosniadou, 1994) can be discerned in astronomical thinking in relation to the structure of the celestial bodies and the regularity that prevails between them (Kuhn, 1962; Linton, 2004; Timberlake, 2013):

Copyright by author(s); $\underline{\text { CC-BY }}$ 
(1) The pre-scientific model - the sky is the place where the gods reside, and whatever happens there represents the will of the gods and the way in which they relate to human actions. Evidence of this model exists from three thousand years B.C.E. and until the beginning of the Greek era in approximately 600 B.C.E.

(2) The geocentric model - the earth is positioned at the centre of the universe, the sun, planets and stars revolve around it. This perception was accepted from the $6^{\text {th }}$ century B.C.E. until the 17 th century A.D.

(3) The heliocentric model - the sun is positioned in the centre of the universe and the planets and stars revolve around it. The invention of the telescope launched the development of this approach. It was the accepted approach in the $17^{\text {th }}$ and $18^{\text {th }}$ centuries.

(4) The stellar model - the universe contains millions of stars and the sun is simply one small star among the universe's stars. The development of large telescopes and improvement of scientific understanding regarding light and matter facilitated the development of this model in the $19^{\text {th }}$ century and the beginning of the $20^{\text {th }}$ century.

Throughout this article, we will frequently use the concepts "conceptual frameworks" (CF) and "mental model." Figure 1 illustrates the difference and relationships between these concepts. The conceptual framework contains two layers, represented along a continuum as concepts (nodes) and links (arcs). The mental model contains four layers, the first two resemble the two layers of the conceptual framework, but usually with richer contents. The four layers of the mental model are:

(1) Concepts

(2) Links - between the concepts

(3) Laws - describing the systematic influence of one concept (or variable) on another concept. Examples include the Law of Gravitation or the Law of Conservation of Linear Momentum

(4) Methods and strategies to transfer the laws and interpretation for new situations (Hestenes, 2006).

Figure 1. The relationships between the "conceptual frameworks" and "mental model."

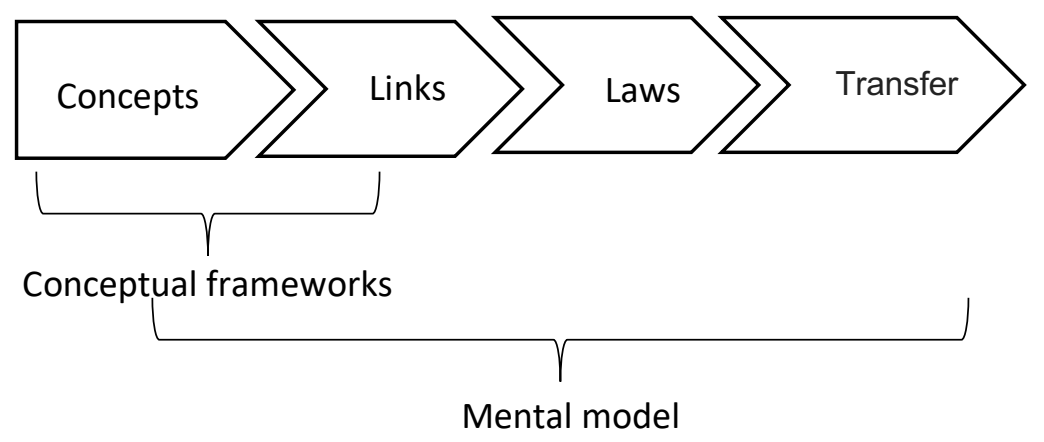

Hestenes $(1987 ; 2006)$ describes the idea of modelling in physics and physics education in some detail. We adopt this theory, with slight modification, to astronomy education. Modelling theory involves the use of four components:

(1) Concepts - events or objects the students are exposed to during their studies. Some of them already known from daily life like: sun, moon, planet and stars. Other concepts, are in many cases totally new for the students such as: Oort cloud, Kuiper belt, cosmic radiation and so on. In some cases the concepts are quite isolated ideas or they may be very specific. For example: the "moon" usually refers to the earth's moon; but, there are more than 170 other "moons" in the solar system.

(2) Links - statements or propositions that combine different concepts. Learning about concepts without creating connections between the concepts often comprises mere memorization of facts. When the learners are able to understand the links between the concepts, their learning becomes more meaningful (Ausubel, 2000). Meaningful learning means that the learner consciously chooses to integrate new knowledge by links with knowledge that the learner already possesses (Novak, 2002). 
(3) Laws - describe the systematic influence of one concept on another concept. There are two aspects to these laws: personal and social. Students and even scientists, in some cases, tend to understand laws according to their personal experiences. These "private laws" may rely on insufficient data or be influenced by preliminary assumptions. It is only after these "private laws" are confronted with the laws of the scientific community, and adjusted respectively, that a scientific law can be adopted.

(4) Transfer - the ability to apply the laws in different situations, and to infer the limitations and advantages of these laws. Effective transfer relies on procedural knowledge of science includes strategies, tactics, and techniques for developing, validating, and utilizing laws (Hestenes, 2006).

According to many scholars, school pupils studying astronomy at different ages relate to the studied subjects by adopting one of the above-mentioned mental models or a mix of several models (Bryce \& Blown, 2006; Finegold \& Pundak, 1991; Špelda, 2015). A pupil may be in transition between two mental models or employ different models when analyzing different astronomical phenomena. When pupils hold a mix of ideas that most of it do not belong to one particular mental model, we prefer to relate to this mix as a conceptual framework. It is possible to identify different intermediate levels in the development of models in astronomy. Table 1 displays the different stages of three astronomical models, on which this article focuses: the geocentric model, the heliocentric model and the stellar/scientific model. For example: a person may adopt the simple geocentric model that describes the earth and the rest of the universe as existing within one spherical shell. In a more complex geocentric model each planet has its own sphere moving with different angular velocity. There is an even more complex geocentric model, according to which each planet moves around two spheres: a primary sphere (deferent) and auxiliary sphere (epicycle) (Oh \& Oh, 2011; Shen \& Confrey, 2010). In a similar manner, the heliocentric and stellar models can be seen as respectively more and more complex as shown in Table 1.

Table 1. Three CFs/models describing students' conceptualisations at different ages when they analyse astronomical phenomena

\begin{tabular}{l|l|l|l}
\hline CF or Model / stage & \multicolumn{1}{|c}{ Simple } & \multicolumn{1}{c}{ Advance } \\
Geocentric & $\begin{array}{l}\text { Model of two spheres. Earth } \\
\text { located motionless at the centre } \\
\text { of the Universe. } \\
\text { A stars' sphere rotates around } \\
\text { the Earth. }\end{array}$ & $\begin{array}{l}\text { In addition to the stars' } \\
\text { sphere there are seven other } \\
\text { spheres for planets and stars }\end{array}$ & $\begin{array}{l}\text { Celestial bodies move in } \\
\text { deferents and epicycles around } \\
\text { the earth }\end{array}$ \\
\hline Heliocentric & $\begin{array}{l}\text { The Sun is the largest body in } \\
\text { the universe located at its' } \\
\text { centre, and all the planets rotate } \\
\text { around it in circular orbits. }\end{array}$ & $\begin{array}{l}\text { The Sun is at the centre of } \\
\text { the universe, and the planets } \\
\text { move around it in elliptical } \\
\text { orbits. }\end{array}$ & $\begin{array}{l}\text { Gravitation is the main } \\
\text { organised force. The Sun is the } \\
\text { heaviest body in the universe } \\
\text { and it influences all the other } \\
\text { celestial bodies. }\end{array}$ \\
\hline Sidereal & $\begin{array}{l}\text { The Sun is only one star among } \\
\text { millions of stars. }\end{array}$ & $\begin{array}{l}\text { The stars are all } \\
\text { distinguished as different } \\
\text { from each other by: radius, } \\
\text { structure, elements, } \\
\text { temperature, and luminosity. }\end{array}$ & $\begin{array}{l}\text { Stars have a 'life cycle' } \\
\text { depending on their mass and } \\
\text { interaction with neighbours. } \\
\text { Some stars are composed of } \\
\text { elements created by previous } \\
\text { generations. }\end{array}$ \\
\hline
\end{tabular}

\section{Previous Studies on Students' Astronomical Conceptual Frameworks and Models}

The scientific learning process involves a combination of observations and interpretations that enable the students to develop their understanding. Students' ability to understand the phenomena that they observe or investigate depends to a large extent on the CFs that they have acquired in relation to the studied phenomenon. Many research studies have been conducted to identify the CFs and models adopted by students and teachers in different scientific fields (Confrey, 1990; McDermott \& Redish, 1999). It transpires that students and teachers often tend to hold one single model, yet they simultaneously move to other model according to the circumstances (Shen \& Confrey, 2010). 
Numerous researchers have attempted to described the nature students' mental models used in making sense of astronomy (Finegold \& Pundak, 1990; 1991; Sadler, 1998; Summers \& Mant, 1995, Trumper, 2000). Taken together, it seems that the students' model undergo change processes when they study astronomical phenomena through experimentation and research. But what is unclear is to what extent are these changes stable?

Stability could depend on the extent of the students' inner conviction. In order to establish students' trust in new conceptual change, it is necessary to convince them that the new models: (a) are correct; (b) that they have advantages over the previous models; (c) that they are relatively simple; and (d) that they can understand them (Posner, Strike, Hewson, \& Gertzog, 1982). In many cases, when these four conditions do not exist, students tend to return to models that they reached by themselves from their life experiences. These are naïve models (Baxter, 1989), that contradict accepted scientific models, and they may have a strong influence on the way that students interpret astronomical phenomena. In these cases, after learning ends and its temporary influence fades, the students will abandon the scientific regularity that was presented to them and return to the naïve model with which they began their studies. Previously, Pundak, Schaham and Herscovitz (2012) described this phenomenon as "fragile knowledge". Teachers who do not identify this phenomenon or ignore it may find that their efforts to teach scientific approaches are not rewarded by the students' assimilation of the learning (Favia, Comins, Thorpe, \& Batuski, D. J. 2014; MCloskey, 1983). The transition from a naïve model to a systematic scientific one is not easy and several researchers have taken some initial steps toward clarifying some of the the issues involved in this transition (Gilbert, 2005; Hestenes, 1987).

Astronomy models may be represented in different ways in the form of graphic illustrations, mechanical systems, simulations, software programs or a system of rules that can be used to conduct mathematical manipulations. A useful model may be comprised of a combination of these different representations. As noted above, people tend to alter their CFs or the scientific models that they hold when certain conditions exist (Linn, 2006; Posner et al., 1982). In this paper, we assume that the scientific model provides a way to represent reality that enables the student to analyse scientific and astronomical phenomena (Hans, Kali \& Yair, 2008), to investigate the correlations between variables (Frigg \& Hartmann, 2006) and to create predictions (Lehrer \& Schauble, 2000).

Thus, the development of CFs and models for astronomy has been the subject of intensive research, relating to various ages from elementary school (Nussbaum \& Novak, 1976), to high school pupils (Shen, Gibbons \& Wiegers, 2003; Summers \& Mant, 1995) and including adults (Agan, 2004; Shen \& Confrey, 2010; Vosniadu, 1991, 1994; Vosniadu $\&$ Brewer, 1990). A study dealing with the development of the CFs of 892 elementary and secondary school pupils in Israel, have done by one of the authors (Pundak, 1990), compared pupils' adoption of four CFs: pre-scientific, geocentric, heliocentric and stellar. Findings indicated that with progress in age, there is a reduction in the percentage of pupils, who hold geocentric CF. The research also revealed that as age progresses there is an increase in the percentage of pupils who hold heliocentric CF. According to these research findings, pre-scientific CF disappeared in high school and approximately $15 \%$ of high school pupils acquired stellar model. The results of this research appear in Figure 2. 
Figure 2. Alteration in the conceptual frameworks for astronomy of 892 junior and senior high school students as measured by Pundak (1990)

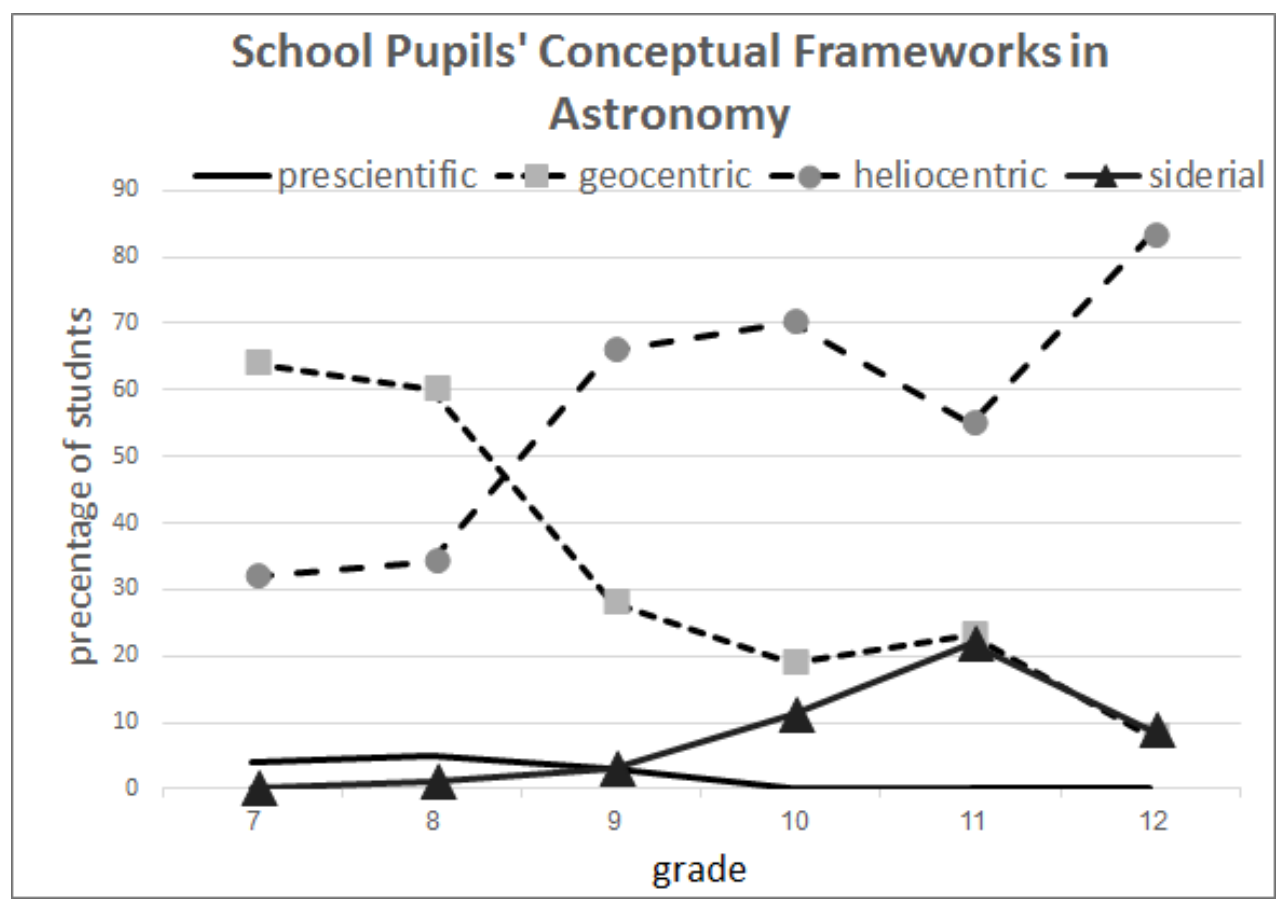

Together, this research highlights the complexity involved in transition from a collection of unconnected scientific concepts to a model that succeeds in clarifying the connection between various astronomical phenomena. While scientists have aspired to develop a model that is able to explain astronomical phenomena with increasing precision a paradigm (Kuhn, 1962) - in many cases, students suffice with the initial explanation for each separate phenomenon, or with the simplest models that are presented to them. For example: a mechanical model of sun-earth-moon facilitates understanding of some of the astronomical phenomena from a heliocentric point of view, but the cost is a deviation from reality because of the mechanical limitations of the model. Models based on software may improve the structure of astronomical knowledge but they are more difficult to understand and are perceived by many students as rather abstract. Moreover, in most schools there are no nightly 'sky observations'; so the discussed astronomical phenomena are mostly presented to the students by the teachers, who act as mediators and tend to guide them to the heliocentric model (Shen \& Confrey, 2010). As explained in the next section, in most cases, the teachers themselves hold a model that is not based on astronomical observations and logical considerations, but on adoption of authorised positions.

\section{Students' and Teachers' Conceptual Frameworks for Astronomy}

What are the CFs in astronomy of elementary teacher and engineering students? In a study conducted in Israel in the last decade, two target populations were investigated: engineering students and elementary school teachers. While there was a marked trend to strong support of the stellar model amongst the engineering students, there was a strong trend towards the heliocentric model among the elementary school teachers.

In a general course on astronomy, 93 engineering students from two colleges responded to the CFA research questionnaire as pre- and post-tests (Pundak, 2016). Most of them were studying in two introductory physics courses: mechanics and electricity and magnetism. Most of the students (65.6\%) had studied astronomy in elementary or secondary schools and another $8 \%$ had never studied astronomy. Their responses allowed the researchers to discern to what extent there was continuity between pupils' conceptualizations in school and those of students in higher education. In comparison to high school pupils, more engineering college students tend to adopt a stellar approach ( $14 \%$ in high schools, $23 \%$ in engineering colleges). In contrast, there was a lower percentage of engineering students 
who adopted a geocentric approach in comparison with the high school pupils (17\% in high school, $5 \%$ in engineering college). These differences can be explained by the influence of physics courses that are studied by engineering students. The students in the physics courses discuss the Law of Gravity and phenomena connected to light and electromagnetic waves. These laws constitute a suitable basis for an understanding of astronomical phenomena.

Another community whose CFs for astronomy were examined was a group of 212 elementary school teachers who were studying in a program that allowed them to complete an academic degree in a college. The program participants taught a range of disciplines in their schools from sciences to humanities. The average age of the teachers was 48.7 years, $83 \%$ were women and $17 \%$ men (Pundak, Rosenfeld, \& Luria, 1995). One of the courses taught in the program was 'History of Science,' and in this course, the learners encountered changes in perception regarding the structure of the universe from Ancient Greece until the $17^{\text {th }}$ century. In the fourth lesson of the course, the learners were taught about the Aristotelian model of the universe's structure. At the beginning of the lesson, learners were asked to provide their opinion of the structure of the universe. Most of them (92\%) employed a heliocentric approach. None of the learners who studied this course and used a heliocentric approach was able to name at least one astronomical phenomenon to support their approach. The Aristotelean model was then presented, and the learners learned to what extent this model explained natural phenomena such as day and night, the seasons, phases of the moon, the movement of planets, etc. Then the learners were asked to oppose the Aristotelean model. Most of them found it difficult to present reasoning that would disprove the Aristotelean model, and they were left with a strong sense of dissonance that stemmed from the contradiction between the attitude they held and the simplicity and elegance of the Aristotelean model. Many of them tended to accept it. A summary of the teachers' notions before and after the discussion of the Aristotelean model appears in Figure 3.

These findings reinforced by later studies (Shen \& Confrey, 2010), which found that science teachers in elementary schools usually hold a heliocentric approach without any ability to ground their attitudes on observations or astronomical knowledge. In many cases, the teachers' notions are determined by what they have learned from parents or teachers because they accept their authority, although they had no background in astronomy. Thus, when they are faced with an authority that suggests a different model, many of them will relatively easily alter their notions. Despite the fact that many of them supported and taught the heliocentric approach, they were willing to adopt the geocentric model when it was presented to them in a reasoned manner as a model that succeeds in explaining many astronomical phenomena. 
Figure 3. The distribution of notions held by learners in an academic programme $(\mathrm{N}=212)$ regarding the structure of the universe. (Notions were examined 'before' the beginning of the course 'History of Science' and 'after' a discussion in the course on the Aristotelean/geocentric approach).

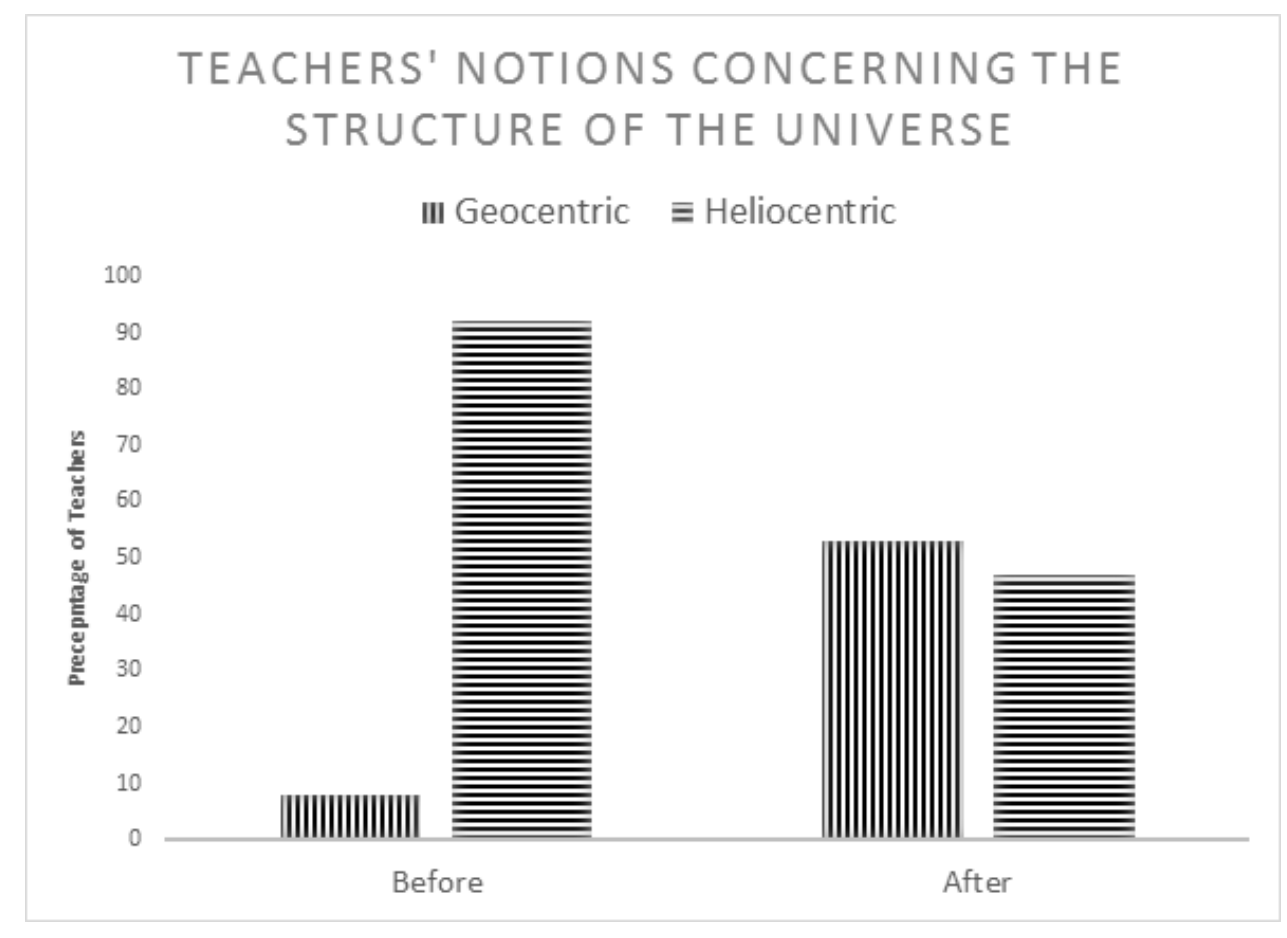

\section{Gap in Knowledge}

This research investigated four models in astronomy held by students in academic colleges in Israel. Examination of the models relied on previous publications in this field (Finegold \& Pundak, 1990, 1991; Pundak, 2016). These previous studies mapped the various stages in the development of CFs for astronomy, and also revealed misconceptions in astronomy and its resources.

In this study, we evaluate converting CF to mental models for astronomy. For this study, we were using the new CFA research instrument (Pundak, 2016). At the CFA there are 23 multiple-choice questions, each is given five-six possible answers. The CFA gives preference to several pre-scientific and geocentric answers. The division of the answers according to percentages is: $32 \%$ pre-scientific answers, $32 \%$ geocentric answers, $17 \%$ heliocentric answers and 19\% sidereal/scientific answers.

\section{The Research Goals}

- To identify and validate astronomical models among college students.

- To evaluate the level of coherence in college students' astronomical models

- To examine the influence of background variables on the student's adoption of a dominant model.

\section{Research Questions}

(1) Is there a distinction between mental models held by college students?

(2) Do students tend to hold a single astronomical model or a mix of them? What is the dominant model held by students?

(3) How do background variables such as 'average academic grade,' 'physics background,' and 'academic discipline' influence the student's adoption of a dominant model? 


\section{METHOD}

\section{Participants}

The present study aims to examine students' mental models regarding astronomical phenomena. Students in three different academic colleges in Israel were selected as sources for the sample: A College of Engineering, a School of Engineering in a second college, and a College of Social Sciences. 537 undergraduates from these three colleges voluntarily participated in the study.

\section{The CFA Assessment Instrument}

Students were asked to respond online to the CFA questionnaire, which constituted the research instrument. The development of the CFA laid on development methods like some other tools. Science Teaching through its Astronomical Roots - STAR instrument (Sadler, 1998), Astronomy Diagnostic Test - ADT - (Zeilik, 2002), TOAST Test Of Astronomy STandards (Slater, 2014), Exam of GeoloGy Standards (Guffey, Slater, \& Slater, 2017). The validation and reliability of the CFA discussed in a previous paper (Pundak, 2016). The questionnaire contained 23 questions referring to four different areas of astronomy: (a) 'Sky observations' - questions dealing with observations of the movement of the sun, moon, and stars ( 7 questions). (b) 'The earth and its orbit' - questions dealing with the position of the earth in the universe, its form, the length of its existence and its future (5 questions). (c) 'The solar system' - questions dealing with the sun, planets, comets, distances from the solar system (5 questions). (d) 'The stars' - questions dealing with the difference between stars and planets, the creation of energy in stars, the length of life of the stars and the phenomenon of supernova (6 questions).

The four possible answers to each of the questions in the questionnaire represent one of the models: pre-scientific, geocentric, heliocentric and stellar/scientific. The last model is represented by an answer combining a choice of the stellar approach or the scientific approach where there is no need for a stellar approach. Cronbach's $\alpha$ revealed a high level of internal reliability: $\alpha=0.84$ for all the instrument's items.

In order to distinguish the respondent's approaches optimally in the context of their astronomical knowledge, according to these four models, the respondent's grade for the questionnaire was calculated according to two different methods:

(1) Calculation according to mean grades: this manner of calculation involved three stages: at the first stage, all possible responses for all questions were sorted according to responses 1-4 representing: prescientific, geocentric, heliocentric, stellar/scientific models respectively. At the next stage, the mean response for all questionnaire items was calculated so that each respondent received a grade between 1 and 4 . At the third stage, the respondents were divided into categories by their mean grade so that all those who received a particular value were assigned to a particular type of mental model. The categorisation was performed as follows: between $1-1.75=$ pre-scientific; $1.74-2.50=$ geocentric; 2.50 $3.25=$ heliocentric and 3.25-4.00=stellar/scientific. This analysis was conducted for the entire questionnaire and also separately for each area of knowledge ('the earth and its orbit', 'the solar system', 'stars', 'sky observations'). The advantage of this method of calculation is that it is simple to calculate and understand the findings. On the other hand, there is also a problem with this method. The problem is some extent of possibility that there may be a deviation of the result for the subject from the "correct" result. We chose to use this method despite the problems in light of its convenience and because of the low probability of deviating from the correct result

(2) Calculation on a relative basis: This type of calculation involved three stages of calculation. The proportion of responses that each student gave for each model was calculated. Thus, if the student provided 10 geocentric responses out of 23 questions in the CFA - their grade for this model would be 0.43 . This analysis was conducted both for the entire questionnaire and also separately for each area of knowledge ('sky observations', 'the earth and its orbit', 'the solar system', 'stars'). 
The fundamental difference between these two calculation methods is that in the calculation based on the mean score, each student has one value for the mental model that categorizes his/her conceptualisation. This approach reflects the paradigmatic approach of Kuhn (1962), according to which people tend to adopt one mental model.

In contrast, in the relative calculation, for each respondent, there are four grades for each of the models so that he/she is not categorized by a particular paradigmatic model. This approach reflects the findings of researchers who note that school pupils and adults tend to hold a mix of models and employ each of them by the question that they are attempting to answer.

\section{RESULTS}

The findings are given according to the two calculation methods described above for each research question.

\section{Part 1: Distinction between Astronomical Models}

The first part of the findings focuses on the question whether there is a statistical distinction between models held by college students. In other words, the question asked is: Do the different models represent distinctly different perceptions of astronomical understanding? If so, which models received high scores and which models received lower scores?

Table 2 presents the results of the analysis by Wilcoxon Signed Ranks Test which was used to compare the four different models.

Table 2. Wilcoxon Signed Ranks Test between the perceptions of four conceptual frameworks for astronomy among college students $(\mathrm{N}=537)$

\begin{tabular}{l|c|c|c}
\hline Conceptual Framework & Mean & S.D & Z \\
\hline Pre-scientific & 0.12 & 0.09 & $-18.52 * * *$ \\
\hline Geocentric & 0.29 & 0.10 & $-10.43 * * *$ \\
\hline Pre-scientific & 0.12 & 0.09 & $-17.41 * * *$ \\
\hline Heliocentric & 0.18 & 0.09 & $-15.34 * * *$ \\
\hline Pre-scientific & 0.12 & 0.09 & \multirow{2}{*}{$-7.93 * * *$} \\
\hline Stellar/scientific & 0.40 & 0.19 & 0.10 \\
\hline Geocentric & 0.29 & 0.09 & $-15.95 * * *$ \\
\hline Heliocentric & 0.18 & 0.10 & 0.19 \\
\hline Stellar/scientific & 0.29 & 0.09 & 0.19 \\
\hline Heliocentric approach & 0.40 & & \multirow{2}{*}{$*$} \\
\hline Stellar/scientific approach & 0.18 & 0.40 &
\end{tabular}

$* p<.05 . * * p<.01 . * * * p<.001$

Table 2 shows that there are significant differences between the means for each of the models about the means for other models. These findings indicate that there was a strong and clear distinction between the levels of the dominance of the four models. The mean of the stellar/scientific model is significantly higher than the means for the three other models. The pre-scientific model and the heliocentric model means are lower than those for the two other models, but there is also a distinction between them. The mean of the geocentric model is the highest among the other three models, but it is below the mean for the stellar/scientific model and distinguished from all the three other models. Thus, there is a clear hierarchy of dominance between the models according to the following order: stellar/scientific, geocentric, heliocentric and pre-scientific.

Table 3 shows the correlations between the different models. 
Table 3. Pearson correlation coefficients between the four astronomical approaches

\begin{tabular}{l|c|c|c}
\hline & Pre-scientific & Geocentric & Heliocentric \\
\hline Geocentric & $.183^{* *}$ & & \\
\hline Heliocentric & $.129^{* *}$ & $.146^{*}$ & $-.617^{* *}$ \\
\hline Stellar / scientific & $-.653^{* *}$ & $-.707^{* *}$ &
\end{tabular}

As can be seen from table 3 all the correlations are significant, and the correlations between the stellar/scientific model and the other models are negative and especially strong. This means that insofar as the respondents receive a higher grade for the stellar/scientific model, they will have a relatively lower grade for the other approaches and vice-versa.

In contrast, there are significant positive correlations at a medium level between the other models. A relatively high grade for one of them indicates a relatively high grade also for the second and vice-versa. These findings show that the stellar/scientific model was distinguished as significantly different from the other models so that anyone who adopted this model in an outstanding manner was completely distant from the other three models.

\section{Part B: A Single Astronomical Model or a Mix of Models?}

The second part of the findings clarifies which is the student's dominant mental model for astronomy for all the CFA items and each of the four areas of knowledge.

Table 4 displays the means and SDs for the respondent's responses for each of the mental models based on the relative analysis method.

Table 4. Means and SDs for dominant approaches to astronomy for all respondents $(\mathrm{N}=537)$

\begin{tabular}{l|c|c|c|c|c|c|c|c}
\hline \multicolumn{1}{c}{ Area of knowledge } & \multicolumn{2}{c}{ Pre-scientific } & \multicolumn{2}{c}{ Geocentric } & \multicolumn{2}{c}{ Heliocentric } & \multicolumn{2}{c}{ Stellar/scientific } \\
& $\mathrm{M}$ & $\mathrm{SD}$ & $\mathrm{M}$ & $\mathrm{SD}$ & $\mathrm{M}$ & $\mathrm{SD}$ & $\mathrm{M}$ & SD \\
\hline General grade & 0.12 & 0.09 & 0.29 & 0.1 & 0.18 & 0.09 & 0.4 & 0.19 \\
\hline 'The earth and its orbit' & 0.14 & 0.17 & 0.28 & 0.19 & 0.07 & 0.11 & 0.52 & 0.29 \\
\hline 'The solar system' & 0.16 & 0.16 & 0.36 & 0.18 & 0.13 & 0.15 & 0.35 & 0.23 \\
\hline 'Stars' & 0.12 & 0.13 & 0.35 & 0.21 & 0.2 & 0.16 & 0.33 & 0.24 \\
\hline 'Sky observations' & 0.09 & 0.12 & 0.2 & 0.15 & 0.29 & 0.15 & 0.42 & 0.22 \\
\hline
\end{tabular}

Figure 4 presents the distribution of students' models according to the four knowledge areas and general grade. In resemblance to the findings in Table 2, the findings in Figure 4 in the parameter of "General grade" indicate that the stellar/scientific model $(40.0 \%)$ is the dominant model, while the pre-scientific model $(12 \%)$ is relatively rare. Moreover, the general structure of the hierarchy of approaches from the most dominant model, which is the stellar/scientific approach through the intermediate geocentric and heliocentric approaches and ending with the prescientific approach, which is the rarest, exists for all four areas of knowledge in astronomy that were studied. 
Figure 4. Distribution of students' $(\mathrm{N}=537)$ perceptions of astronomy according to dominant mental models (The distribution relates to all the research questionnaire questions and to four areas of knowledge represented in CFA).

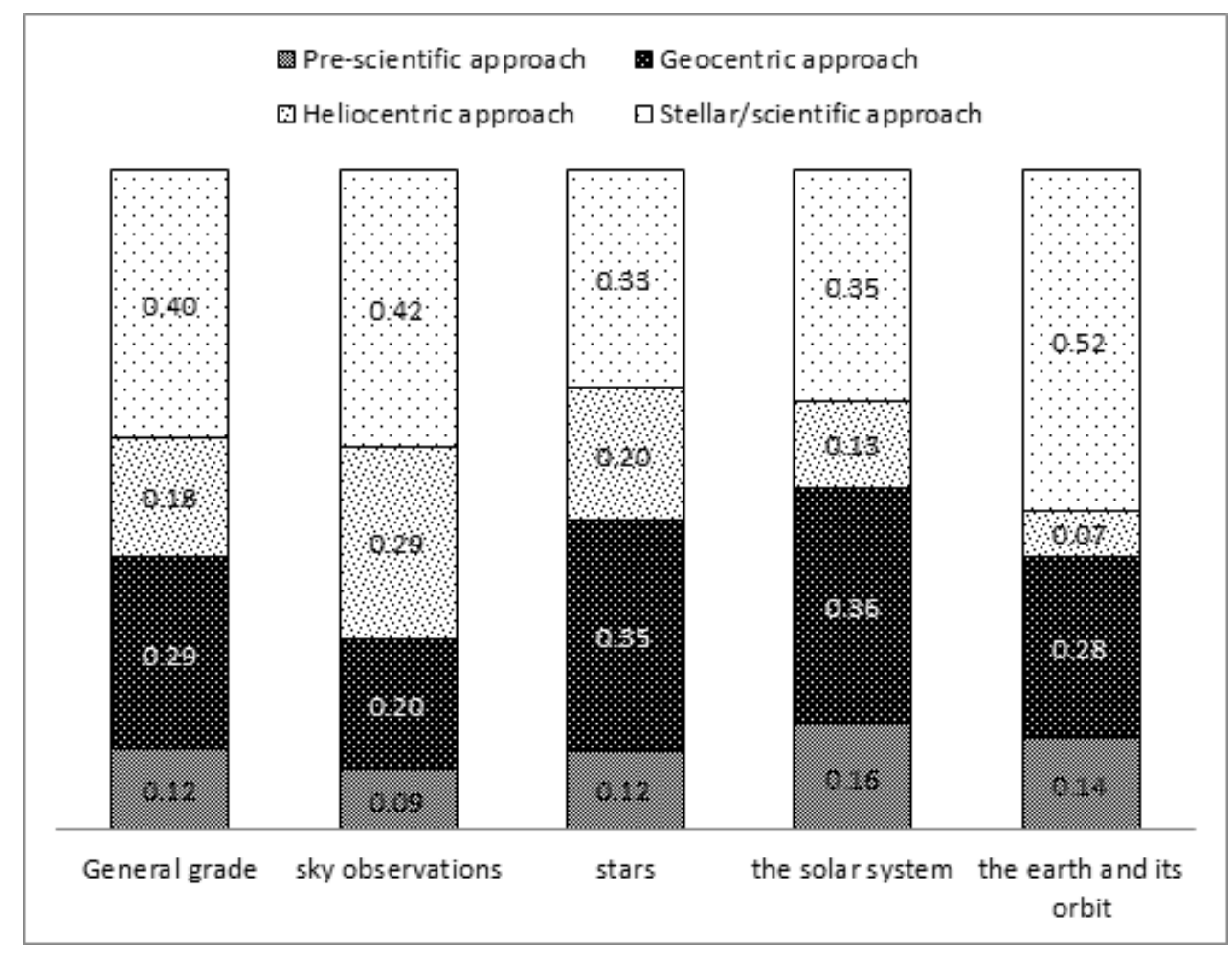

The distribution that indicates the dominance of the different models is replicated in the four studied areas, but there is a significant difference in the grades given for each area of knowledge. Thus, while the pre-scientific model received a relatively very low grade (9\%) about 'observations,' with regard to 'the solar system' it rises to $16 \%$. The geocentric approach had a medium level although obvious difference can be seen in the different areas: while for 'observations', it was relatively low (only $20 \%$ ), for 'the solar system' it reached $36 \%$. The heliocentric approach exhibits a similar behavior: while for 'the earth and its orbit' it had a low frequency (7\%), for 'observations' it was far more frequent $(29 \%)$. The difference was also evident in the stellar/scientific approach, despite the fact that it was the dominant model for all knowledge areas, yet for 'the earth and its orbit' it increased to a frequency of 52\%, while for the 'stars' its frequency dropped to $33 \%$. The results support the idea that college students adopt mixed astronomical models, which will be discussed later.

Figure 5 presents a comparison between results of the present study dealing with college students and findings from previous research (Pundak, 1990) relating to school pupils, according to the means-based analysis method.

From Figure 4 and Figure 5 it can be seen, there is a significant contradiction between the findings emerging from the two methods of analysis. While in the mean-based analysis in Figure 5, the dominant model is the heliocentric model; in the relative analysis in Figure 4, the dominant model is the stellar/scientific. Discussion of the advantages and disadvantages of the two analysis methods to explain the possibilities they embody can help elucidate this contradiction. The mean-based analysis is a method that was found suitable for analyses performed in previous studies, It permits comparison of the processes involved in the choice of a model for astronomy between different populations and ages (Finegold \& Pundak, 1990, 1991; Pundak, 2016; Sadler, 1998; Trumper, 2000; Zeilik, 2002).

Figure 5 also presents a comparison of CFs for astronomy between high school pupils (previous study) and college students (this study). From the data in Figure 5 it is possible to discern alteration in the dominance of the geocentric model that gradually weakens in the transition from junior high school to senior high school and strengthens again 
among college students. A mirror image occurs about the heliocentric model which strengthens in high school but weakens in college.

Figure 5. Conceptual framework in astronomy, comparison between results of the present study dealing with college students and findings from previous research (Pundak, 1990) relating to school pupils, according to the means-based analysis method.

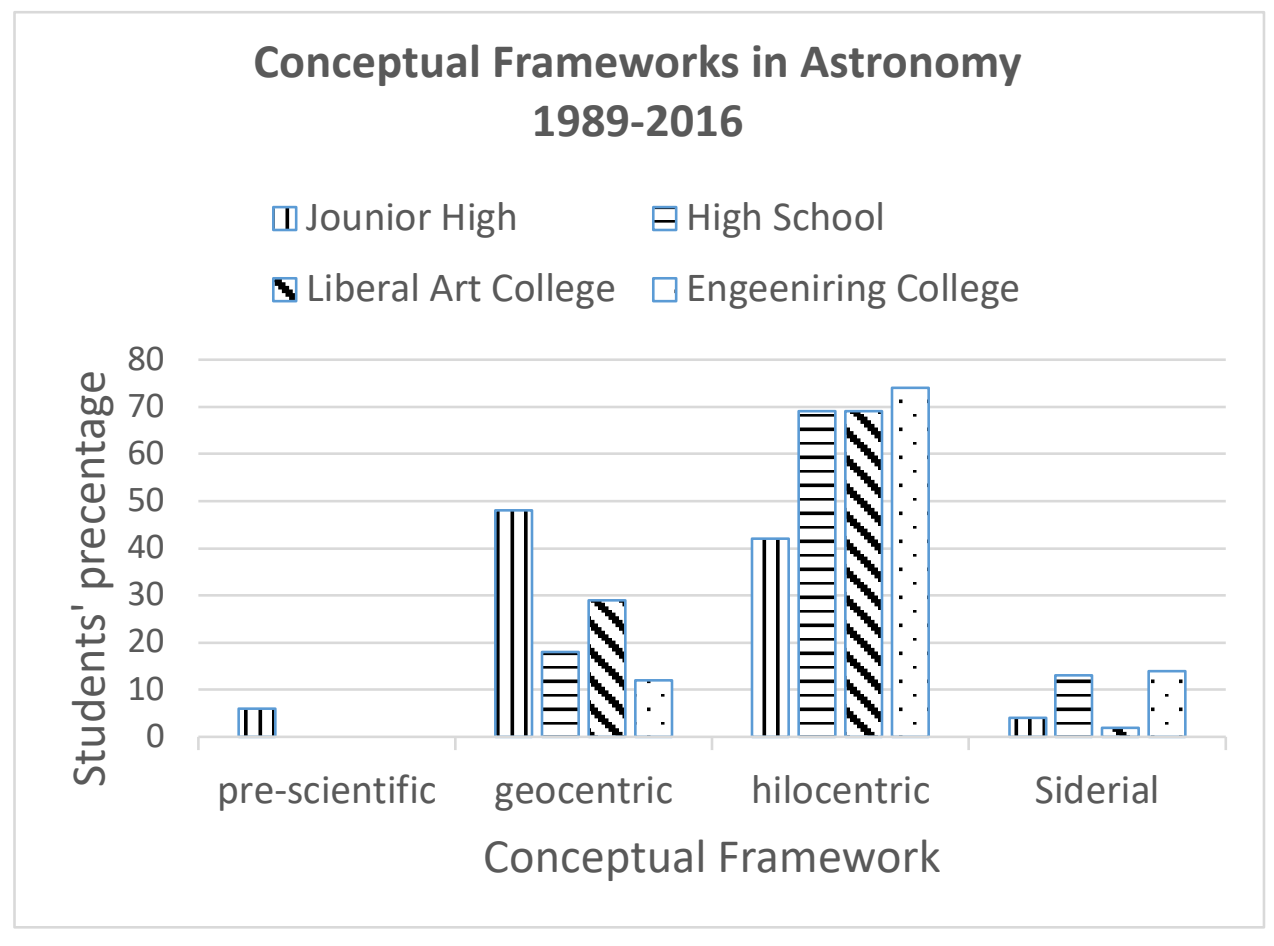

\section{Part C: The Influence of Background Variables on the Students' Mental Models}

In order to understand the students' preference of mental models, students from different disciplines were chosen for this study. The background variables that influence the choice of the dominant model were examined. The background variables that were examined include: 'average academic grades', 'age', 'gender', 'scientific background', and 'academic disciplines'. Identification of the correlations between the background variables and the astronomical models adopted by the students can deepen our knowledge about the development of astronomical perceptions.

At the first stage, Mann-Whitney Tests were performed to find differences between groups, i.e. to examine the difference between those who had studied introductory physics courses and those without such a background. This analysis is based on the assumption that a student who studied an introductory course in physics should adopt more scientific model than a student that has not studied such a course (Hestenes, 2006), Table 5 shows the results of MannWhitney Tests comparing the two populations of students.

The findings shown in Table 5 indicate a significant distinction between those who have a background in physics and those who do not for each of the studied areas. While those who have a background in physics tend to adopt a stellar/scientific approach in a significant manner, those who lack a background in physics significantly adopt the other models. The stellar/scientific mental model is the dominant model among those who have a physics background $47 \%$, while the pre-scientific model is less often adopted and only $10 \%$ employ it to analyze astronomical phenomena. Thus, there is a gap of $37 \%$ among these students between the two models. Among those with no physics background, this gap diminishes to $21 \%$ (for the stellar/scientific approach $-35 \%$ and for the pre-scientific approach - $14 \%$ ). These findings mean that regarding the extent of adoption of the stellar/scientific approach there is a significant difference between those with a physics background and those without such a background.

Copyright by author(s); $\underline{\text { CC-BY }}$

The Clute Institute 
Table 5. Mann-Whitney Test to identify differences in approaches between those who have or lack a background in physics

\begin{tabular}{|c|c|c|c|c|c|}
\hline \multirow[t]{3}{*}{$\begin{array}{c}\text { Astronomical } \\
\text { Approach }\end{array}$} & \multirow{2}{*}{\multicolumn{2}{|c|}{$\begin{array}{c}\text { No physics background } \\
(\mathrm{n}=312)\end{array}$}} & \multirow{2}{*}{\multicolumn{2}{|c|}{$\begin{array}{l}\text { Have a physics background } \\
\qquad(\mathrm{n}=225)\end{array}$}} & \multirow[b]{3}{*}{$\mathbf{Z}$} \\
\hline & & & & & \\
\hline & M & S.D & M & S.D & \\
\hline Pre-scientific & 0.14 & 0.09 & 0.1 & 0.09 & $5.66^{* * *}$ \\
\hline Geocentric & 0.31 & 0.1 & 0.27 & 0.1 & $3.87^{* * *}$ \\
\hline Heliocentric & 0.2 & 0.08 & 0.16 & 0.09 & $4.45^{* * *}$ \\
\hline Stellar-scientific & 0.35 & 0.17 & 0.47 & 0.2 & $-6.68^{* * *}$ \\
\hline
\end{tabular}
$* p<.05 . * * p<.01 . * * * p<.001$

Table 6. Differences between students in different fields of study in the distribution of their mental model

\begin{tabular}{|c|c|c|c|c|c|}
\hline \multirow[t]{2}{*}{ Area Of Knowledge } & & \multicolumn{4}{|c|}{ Conceptual Framework } \\
\hline & & Pre-Scientific & Geocentric & Heliocentric & Scientific \\
\hline \multirow{2}{*}{ 'The earth and its orbit' } & Social Sciences & $17.5 \%$ & $32.8 \%$ & $7.0 \%$ & $42.7 \%$ \\
\hline & Engineering & $9.3 \%$ & $22.3 \%$ & $6.7 \%$ & $61.7 \%$ \\
\hline \multirow{2}{*}{ 'Sky observations' } & Social Sciences & $11.2 \%$ & $21.1 \%$ & $31.7 \%$ & $35.9 \%$ \\
\hline & Engineering & $7.4 \%$ & $19.3 \%$ & $25.8 \%$ & $47.4 \%$ \\
\hline \multirow{2}{*}{ 'The solar system' } & Social Sciences & $19.6 \%$ & $36.2 \%$ & $16.1 \%$ & $28.1 \%$ \\
\hline & Engineering & $13.0 \%$ & $35.5 \%$ & $9.7 \%$ & $41.8 \%$ \\
\hline \multirow{2}{*}{ 'Stars' } & Social Sciences & $12.6 \%$ & $38.1 \%$ & $21.2 \%$ & $28.0 \%$ \\
\hline & Engineering & $10.7 \%$ & $32.4 \%$ & $19.2 \%$ & $37.7 \%$ \\
\hline \multirow{2}{*}{ General grade } & Social Sciences & $14.8 \%$ & $31.4 \%$ & $20.2 \%$ & $33.6 \%$ \\
\hline & Engineering & $9.9 \%$ & $26.9 \%$ & $16.5 \%$ & $46.8 \%$ \\
\hline
\end{tabular}

We also examined the difference between students studying different academic disciplines. The research hypothesis was that in the different academic disciplines the students acquire different tools to construct their astronomical approaches. In two colleges, the research participants were mainly engineering students while in the third college the participants were mainly liberal arts students. The findings indicated the same structure of dominance for the different models in all the groups but this appeared more moderate in the two groups studying humanities and social sciences in contrast to the group of students studying natural sciences/engineering.

\section{Part D: Prediction of The Stellar/Scientific Mental Model through Background Variables}

To gain a more profound understanding of the student's ability to develop a stellar/scientific model, we calculated squared linear regressions. This analysis is based on the theory that the concept of this model develops following the learner's previous scientific studies. Therefore, two indicators are used for the prediction test, which indicates previous scientific knowledge ('background in physics' and 'academic discipline') and a third variable that indicates mean academic grade. The following are the results of the regression analysis:

Table 7 indicates that the predictive model is very significant, meaning that it is possible to predict the level of the stellar/scientific model held by the students through the three studied background variables. In contrast, the level of explained percentage of difference is not significantly high. In other words, there are still many variables that could help to improve the predictive ability of this variable. Among the predictive variables, it can be seen that the most significant variable is the 'academic discipline', which the student studies, i.e. studies in natural sciences constitute a primary factor that facilitates the student's understanding of the astronomical system through scientific tools. A second factor that constitutes a significant prediction factor is the student's academic grade. According to these findings, when the student has a higher mean grade, there is a higher probability that the student will have a stronger stellar/scientific perception. 
Table 7. Squared linear regression to predict the stellar/scientific mental model

\begin{tabular}{|c|c|c|c|c|c|}
\hline \multicolumn{6}{|c|}{ Stellar/scientific mental model for astronomy } \\
\hline The variable & B & SE B & $\beta$ & $\mathbf{T}$ & \\
\hline Background in physics & .05 & .03 & .15 & 1.85 & \\
\hline Mean academic grade & .00 & .00 & .12 & $2.25^{*}$ & \\
\hline Discipline studied by respondent & 1.0 & .03 & .26 & $3.17^{* * *}$ & \\
\hline $\mathrm{R}^{2} \mathrm{~T}-\mathrm{T}-\mathrm{T}^{2}$ & & & & & .13 \\
\hline $\mathrm{F}$ & & & & & $22.41^{* * *}$ \\
\hline
\end{tabular}

\section{CONCLUSIONS}

The results of this study provide community insight in four domains:

1. Efforts to clarify the difference between the CFs and mental model during the development of astronomical knowledge among college students.

2. Using a new tool to examine the 4 mental models - The study uses a new research instrument - the CFA, developed by Pundak (2016) which measures the application of CFs and mental models in astronomy. The CFA can be used as a research tool in other cultures and populations, to clarify scientific approaches to astronomy. The present study examined different aspects of college students' interpretation of astronomical phenomena. The findings that most college students held mixed astronomical models and employed a different mental model in different astronomical areas, are innovative findings. The study examines the differences between the mental models of students from different disciplines, differences not found in previous studies.

3. Two ways of calculating the findings in order to deepen understanding: according to means and on a relative basis. The paper describes the advantages and disadvantages of each approach.

4. Examining the background variables that contribute to the adoption of the scientific model - The new insights derived from this research may be significant for the development of science teaching. Due to the great difficulty involved in the perception of astronomical phenomena, the teaching of astronomy should encourage discussion between learners, sharing ideas and reasoning and allowing them to expose the mental models that guide them in understanding these phenomena. By doing so, students could become aware of any contradictions in the approach that they adopt when they explain astronomical phenomena, and this can enhance deep conceptual understanding. Those of them who strive for more coherence in their explanations may move toward a more consistent astronomical model.

\section{The Connection between the History of Astronomy and Astronomical Mental Models}

The many experts (Gingerich, 2004; Hoskin, 1999; Kuhn, 1962; Linton, 2004), who has analyzed the history of astronomy, have distinguished several different periods characterized by different models of the universe: mythological, geocentric, heliocentric and stellar. Relying on these models, studies of learners of different ages (Agan, 2004; Bryce \& Blown, 2004; Calderón, Flores \& Gallegos, 2013; Nussbaum, 1989; Vosniadu, 1994; Zeilik, 2002), have contributed to a more profound understanding of the way in which CFs for astronomy develop. In the present study, we examined the extent of the distinction between these models. The results indicate the existence of a significant statistical difference between the four mental models. This finding supports the existence of a difference in the students' adoption of the four different models and provides grounding for the assumption that these four different models exist among the students' perceptions. Moreover, the finding is in line with findings from previous studies in this field (Oh and Oh, 2011; Finegold \& Pundak, 1990; Piaget, 1973).

\section{A Single Model Versus A Mix Of Models}

Astronomy deals with a broad variety of phenomena spread over very wide scales of: distances, density, radiation intensity, temperature, and pressures. To understand astronomical phenomena, the student is required to have knowledge of many scientific phenomena and to be able to form many links from atomic phenomena to explosions of 
immense energy. The present study investigated the way in which students perceive astronomical phenomena within four knowledge areas, using the CFA research tool.

The research findings were processed according to two approaches: a single model or mix of models. The first approach assumes that each learner holds a single mental model that he uses to react to or analyze astronomical phenomena. The second approach assumes that each student adopts a mix of mental models and uses them in line with the phenomena that they are asked to consider. The findings show that in most cases, students do not adopt a single model, rather a mix of models. The use of a particular model out of a 'personal mix' depends on the context in which the discussion takes place. This is far more so among the liberal arts students in comparison to engineering students. This interpretation of the findings based on three components. (a) A review of the literature relating to astronomy (Oh and Oh, 2011; Sadler, 1998; Shen and Confrey, 2010). (b) The existence of a significant distinction between the studied astronomical models held by the students, as discussed in the previous section. (c) For each of the four studied areas, there is a different mix of mental models. In other words, it is not just that the learners hold a mix of CFs but also this mix is not organized, and there is a large amount of difference in the application of these CFS.

There is a significant difference in astronomical interpretation between professional astronomers and college students. Astronomers, as long as they deal with subjects that are not at the forefront of the science, adopt a single model that represents the map of norms accepted in the scientific community at a particular time. However, when speaking about college students from different disciplines, for whom astronomy is not their main discipline, each of them develops a personal conceptual framework concerning the astronomical phenomena studied in this research.

\section{Modeling at Social Science versus Natural Science Students}

The study reveals that science/engineering students are closer to the stellar/scientific model, and also their 'model mix' has a stronger tendency to be more homogeneous compared to the mix employed by social sciences students, who have not studied introductory science courses. The research investigated to what extent different background variables such as: 'mean academic grade', 'year of studies', 'background in physics', and the 'academic institute' where the student studies, constituted factors that influenced or distinguished the development of the stellar/scientific model, which is the model accepted today by astronomers. The findings indicated the influence of 'background in physics.' Physics introductory courses had a positive influence on the students' tendency to adopt the stellar/scientific model. These findings were examined in light of learning theories and previous research.

The Constructivist approach that describes how learning processes develop includes two main components: (a) the development of the ability for abstraction (Piaget, 1929, 1930, 1973) and (b) social learning processes (Vygotsky, 1980). In teaching science-learning processes instructor try to develop the best possible thinking processes with regard to the structure of the world, such as are acceptable to the scientific community (Redish, 1998). Each school pupil undergoes a personal science learning process, gradually constructing their personal conceptualization through consistent dialogue with their learning group, and with their more distant social environment, some of which is accessed through the Internet and some from textbooks, in scientific journals or other forms of media. In introductory science courses, students are exposed to simplified CFs that create a description of reality. Helped by their conceptual map created through the learning process, a picture of reality is gradually constructed, exposing rules that enable prediction of processes relating to natural sciences in general and in particular to astronomy.

The research findings support the idea that the contribution of engineering courses to the development of an understanding of astronomical phenomena is greater than the contribution of social sciences or the humanities. Despite the great importance of social sciences and humanities, the overlap between their CFs and the laws they produce, and astronomical models is lower in comparison with the models and laws studied in natural sciences and engineering. These findings indicate the need to bring the fundamentals of astronomy to broad audiences, who have no scientific background. It is reasonable to expect that these audiences will succeed in analyzing astronomical phenomena to a lesser extent than students who have the privilege to study courses in sciences and engineering. 


\section{Background Variables That Contribute to the Development of a Stellar/Scientific Mental Model}

The research findings indicated that all three studied variables ('academic discipline', 'introductory courses in physics' and 'academic grade') had a positive influence on the development of a mental model.

The contribution of 'studies in natural sciences and engineering' was the most important contribution. A possible explanation of this could be the background in 'physics introductory courses' was insufficient to assist the development of the stellar/scientific model rather it was actually a variety of scientific/engineering studies that assisted the students to develop their mental model.

Another factor that was important in explaining the adoption of this model was the student's academic achievements over the period of their academic studies. In other words, it is possible to assume that the student's mean academic grade reflects their level of ability to make abstractions (Summerlee \& Murray, 2010), allowing students with higher academic achievements to construct a better conceptual framework in comparison to students with lower academic achievements.

\section{Further Research}

The research leaves certain questions unanswered for further research: which astronomical CFs or models do students in other disciplines hold? Are there similar models held by students in other world states, so that is possible to generalize results of this study to similar communities abroad? Why do introductory courses in physics have a relatively small influence on the development of the stellar/scientific model?

\section{AUTHOR BIOGRAPHIES}

Dr. David Pundak is a Senior Lecturer in Physics and faculty in Kinneret College (KC) and Head of E-Learning Unit in ORT Braude College. Dr. Pundak founded the Centre for Science and Astronomy Education at KC. The center integrates research performed by scientists with inquiry projects conducted by junior-high and senior-high school pupils. Email: E-mail: dpundak@gmail.com (Corresponding author).

Ido Lieberman, Ph.D., is a Lecturer in Sociology and Statistics at Western Galilee College, Israel. His main specialization is the methodology of social research and statistics. He also researches demographic trends in Israeli society, studies in the post-modern era and evaluation research in organizations.

Dr. Miri Shacham is a senior lecturer in Education and Psychology in ORT Braude College of Engineering. Her main research domains are teaching and learning in higher education and Trauma and Resilience. Dr. Shacham manages a special personal-academic program for students in their first academic year.

\section{REFERENCES}

Agan, L. (2004). Stellar ideas: Exploring students' understanding of stars. Astronomy Education Review, 1(3), 77-97. Ausubel, D. P. (2000). The acquisition and retention of knowledge. Dordrecht: Kluwer.

Baxter, J. (1989). Children's understanding of familiar astronomical events. International Journal of Science Education, 11(5), 502-513.

Bryce, T.G.K., \& Blown, E.J. (2006). Cultural mediation of children's cosmologies: A longitudinal study of the astronomy concepts of Chinese and New Zealand children. International Journal of Science Education. 28(10), 1113-1160.

Calderón, C. E., Flores, C. F., \& Gallegos, C. L. (2013). Elementary students' mental models of 'the solar system'. Astronomy Education Review, 12(1) DOI: 10.3847/AER2012044.

Confrey, J. (1990). A review of the research on student conceptions in mathematics, science, and programming. In C. B. Cazden (Ed.), Review of Research in Education, 16, 3-55. Washington, DC: American Educational Research Association

Favia, A., Comins, N.F., Thorpe, G.L., \& Batuski, D.J. (2014). A direct examination of college student misconceptions in astronomy: A new instrument. Journal and Review in Astronomy Education and Outreach, 1(1), A21-A39.

Finegold, M., \& Pundak, D. (1990). Students' conceptual frameworks in astronomy. Australian Science Teachers Journal, 36(3), 76-83. 
Finegold, M., \& Pundak, D. (1991). A study of change in students' conceptual frameworks in astronomy. Studies in Educational Evaluation, 17, 151-166

Frigg, R. \& Hartmann, S. (2006). Models in science. In E.N. Zalta (Ed.), Stanford encyclopedia of philosophy. Stanford University, Metaphysics Research Lab. http://plato.stanford.edu/

Gilbert, J. K. (Ed.). (2005). Visualization in science education (Vol.1): Models and modeling in science education. Dordrecht, the Netherlands: Springer.

Gingerich, O. (2004). The book nobody read. NYC, USA: Walker Publishing Company, Inc.

Guffey, S.K., Slater, T.F., Slater, S.J. (2017). Development of Tte EGGS Exam of GeoloGy Standards to measure students' understanding of common geology concepts. Journal of Astronomy \& Earth Sciences Education, 4(1), 25-62. DOI: http://dx.doi.org/10.19030/jaese.v4i1.9973

Hans, M., Kali, Y., \& Yair, Y. (2008, March) Spatial perception of the moon phases: Designing a web-based module for middle school students. Paper presented at the Annual Conference of American Educational Research Association, New York City.

Hestenes, D. (1987). Toward a modeling theory of physics instruction. American Journal of Physics, 55, 440-454.

Hestenes, D. (2006). Notes for a Modeling Theory of Science, Cognition and Instruction. Proceedings of the 2006 GIREP Conference: Modelling in Physics and Physics Education.

Hoskin, M. (1999). Astronomy in antiquity. In M. Hoskin (Ed.), The Cambridge concise history of astronomy. New York: Cambridge University Press.

Kuhn, T. S. (1962). The structure of scientific revolutions. Chicago: University of Chicago Press.

Lehrer, R., \& Schauble, L. (2000). Modeling in mathematics and science. In R. Glaser (Ed.), Advances in instructional psychology (Vol. 5, pp. 101-159). Mahwah, NJ: Lawrence Erlbaum.

Linn, M. C. (2006). The knowledge integration perspective on learning and instruction. In R. K. Sawyer (Ed.), The Cambridge Handbook of the Learning Sciences (pp. 243-264). New York: Cambridge University Press.

Linton, C. M. 2004, From Eudoxus to Einstein: A history of mathematical astronomy. Cambridge, UK: Cambridge University Press.

McCloskey, M. (1983). Naive theories of motion. In D. Gentner \& A. L. Stevens (Eds.), Mental models (pp. 299-324). Hillsdale, NJ: Lawrence Erlbaum

McDermott, L. C., \& Redish, E. F. (1999). RL-PER1: Resource letter on physics education research. The American Journal of Physics, 67, 755-767.

Novak, J.D. (2002). Meaningful Learning: The Essential Factor for Conceptual Change in Limited or Inappropriate Propositional Hierarchies Leading to Empowerment of Learners. Science Education, 86, 548-571.

Nussbaum, J., \& Novak, J. D. (1976). An assessment of children's concepts of the earth utilizing structured interviews. Science Education, 60(4), 535-550.

Nussbaum, J. (1989). The earth as a cosmic body. In R. Driver, E. Guesne, \& A. Tiberghien (Eds.). Children's ideas in science (pp. 170-192). Milton Keynes: Open University Press

Oh, P.S., \& Oh, S.J. (2011). What teachers of science need to know about models: An overview. International Journal of Science Education, 33(8), 1109-1130.

Piaget, J. (1929). The child's conception of the world. London, UK: Routledge \& Kegan Paul.

Piaget, J. (1930). The child's conception of physical causality. London, UK: Routledge \& Kegan Paul.

Piaget, J. (1973). The origins of intelligence in children. New York: W.W. Norton.

Posner, G.J., Kenneth A., Hewson, P.W. \& Gertzog, W.A. (1982). Accommodation of a scientific conception: Toward a theory of conceptual change. Science Education, 66(2), 211-227.

Pundak, D. (1990). A study of change in high school students' conceptual frameworks in astrophysics, by means of student matriculation projects in astrophysics. Ph.D. Dissertation, The Technion, Technology Institution, Haifa, Israel.

Pundak, D. (2016). Evaluation of conceptual frameworks in astronomy. Problems in Education of 21 $1^{\text {st }}$ Century, 69(2), 57-75. Retrieved from: http://oaji.net/articles/2016/457-1460962078.pdf

Pundak, D. Rosenfeld, S., \& Luria, Y. (1995): Changes in science teachers' naïve ideas as a result of conducting a mini-research project in astronomy. Dapim - Journal for Theory and Research in Education, 21, 7-34.

Pundak, D. Schaham, M., \& Herscovitz, O. (2012). Engineering students - Reading habits and fragile knowledge. International Conference on Engineering Education 2012 - Proceedings Turku Finland, July 30 - August 3, 2012.

Redish, E. (1998). Building a science of physics teaching. Millikan award lecture, AAPT Summer Meeting.

Sadler, P. M. (1998). Psychometric models of student conceptions in science: Reconciling qualitative studies and distractordriven assessment instruments. Journal of Research in Science Teaching, 35(3), 265-296.

Shen, J., \& Confrey, J. (2010). Justifying alternative models in learning astronomy: A study of K-8 science teachers' understanding of frames of reference. International Journal of Science Education 32(1), 1-29.

Slater, S. J. (2014). The development and validation of the Test Of Astronomy STandards (TOAST). Journal of Astronomy \& Earth Sciences Education, 1(1), 1-22. DOI: http://dx.doi.org/10.19030/jaese.v1i1.9102

Špelda, D. (2015). From closed cycles to infinite progress: Early modern historiography of astronomy. History of Science, 53(2). 209-233.

Copyright by author(s); $\underline{\text { CC-BY }}$ 
Summerlee, A., \& Murray, J. (2010). The impact of enquiry-based learning on academic performance and student engagement. Canadian Journal of Higher Education, 40(2), 78-94.

Summers, M., \& Mant, J., (1995). A misconceived view of subject matter knowledge in primary science education: A response to Golby et al. 'Some researchers' understanding of primary teaching'. Journal Research Papers in Education, 10(3), 303307.

Timberlake, T.K (2013). Modeling the history of astronomy: Ptolemy, Copernicus, and Tycho. Astronomy Education Review, 12(1), DOI: 10.3847/AER2013001

Trumper, R. (2000). University students' conceptions of basic astronomy concepts. Physics Education, 35, 9-15

Vosniadou, S. (1991). Conceptual development in astronomy. In S. M. Glynn, R. H. Yeany \& B.Britton (Eds.) The psychology of learning science (pp. 149-177). Hillsdale, NJ: Lawrence Erlbaum Associates.

Vosniadou, S. (1994). Capturing and modeling the process of conceptual change. Learning and Instruction, 4, 45-69.

Vosniadou, S., \& Brewer, W. F. (1990). A cross-cultural investigation of knowledge acquisition in astronomy: Greek and American data. In H. Mandl, E. Decorte, N. Bennett \& H. Friedrich (Eds.), Learning and instruction: European research in an international context (Vol. 3, pp. 605-629). Oxford, England: Pergamon.

Vygotsky, L. (1980). Mind in society, the development of higher psychological processes. Cambridge, Massachusetts, London, England: Harvard University Press.

Zeilik, M. (2002). Birth of the Astronomy Diagnostic Test: Prototest evolution, Astronomy Education Review, 1(2), 46. Retrieved http://aer.noao.edu/AERArticle.php?issue $=2 \&$ section $=2 \&$ article $=5$ 